\title{
Stories from Experience: Using the Phenomenological Psychological Method to Understand the Needs of Victims of the Fukushima Nuclear Accident
}

\author{
Michael Edwards
}

\begin{abstract}
In order to assist the victims of the Fukushima Daiichi nuclear disaster, we first need to understand people's lived experiences of the disaster in its social, cultural, and historical context. In this article I outline how phenomenological psychology, a qualitative research approach based upon in-depth interviewing, can be the source of such knowledge. Case vignettes highlight the unique psychological situation of seven individuals, with implications for helping victims of this disaster more generally. KEYwORDs: phenomenological psychology, nuclear accidents, disaster relief.
\end{abstract}

The PeOple of the Tohoku Region, the people of JAPAN, AND many people around the world witnessed the overwhelming traumatic events and aftermath of the triple disaster (earthquaketsunami-nuclear) that occurred in March 2011. What made this disaster unique was not just the scale of destruction and suffering, but the complex trauma involved that included the special situation of a dangerous nuclear reactor accident. To a significant extent, the traumas that particular communities experienced depended upon where in Tohoku they were located. People impacted mostly by the nuclear accident had different experiences from those more directly affected by the tsunami.

As a psychiatrist and researcher interested in how people perceive nuclear power and technology, I felt honored and privileged to be able to visit Fukushima and Tokyo to conduct interviews during the first anniversary period, where I could listen to and record the stories of a small number of Japanese- and Englishspeaking people directly affected by the incidents at Fukushima Daiichi. These stories revealed fears of the effects of an invisible 
danger on current and future generations, feelings of uncertainty and a desperate need to know the "facts" about the likelihood of radiation causing harmful effects, and emotional distress associated with the experience of family and community becoming divided. They also highlighted suspicion toward government, conveying a need for trustworthy and reliable leadership at a time when national livelihood was felt to be threatened.

At first glance, it might appear difficult or even inappropriate to attempt to artificially separate the psychological effects of the nuclear accident from those of the devastating earthquake and tsunami, but as I show below, when we ask people specifically about the nuclear accident, they are able to focus on this particular experience in order to tell what it was like for them. In people's narratives, specific meanings of the nuclear accident do emerge.

In conducting research into disaster and psychological trauma, various approaches can be employed. In this article, I illustrate the potential of a phenomenological psychological approach, where accepting subjective experience and carefully listening to stories gives us direct knowledge of human psychological reality, as well as a potential way of helping victims. ${ }^{1}$ Recording and analyzing stories of lived experience fits within the research paradigm of "human science" rather than natural science and is now an important paradigm in contemporary psychology (Polkinghorne 1983). Although the data contained in the case vignettes below are unanalyzed from a qualitative research point of view, they are valuable nonetheless in opening up the world of experience from which genuine and deep psychological understanding of this nuclear accident can begin to occur. Experiences of the interview approach used here were positive and enlightening for participants as well as myself and validated the impression that professional responses attuned to the needs of those we are endeavoring to assist are well placed to have positive effects.

Within the phenomenological approach, the importance of empathically attuning to people's experiences implies an initial "need to unknow"-or to hold in abeyance-our assumptions about what may be causing the observed experiences, whether they are "pathological" or not, or how we might normally respond to such trauma according to Western psychological and psychi- 
atric therapeutic systems. Of course, there are time-tested ways of helping trauma victims generally, but not in terms of nuclear accidents specifically. I argue that we must also understand the possibly unique characteristics of nuclear traumas by listening. Having said this, all experience occurs in a context, and awareness of the historical, social, and cultural-linguistic context of experience is critical, especially for those of us from distant lands.

\section{Western Models of Psychological Trauma and Nuclear Accidents}

In Western psychology, psychological problems are generally located within the individual. The focus is on ridding the patient's mind of "symptoms" thought to be caused by some pathological dis-ease within the brain. Treatment aims to "normalize" peopleto remove the abnormal pathology. But in any major environmental trauma, it is largely external events and later situations that arise that relate to the onset of "symptoms." The term "pathological" must be applied with great caution here, and in the case of nuclear accidents, we actually know very little about the "typical" experiences and psychological responses that occur. These conditions justify a phenomenological approach that focuses on listening to and faithfully describing lived experience as a primary source of knowledge regarding the psychological effects of nuclear trauma.

It has been suggested that the nuclear accident at Fukushima Daiichi-with the ensuing release of radiation, displacement of the population, and loss of livelihood - can be understood and responded to like any other trauma. The people most affected develop symptoms such as anxiety, depression, and insomnia, or perhaps a syndrome such as post-traumatic stress disorder. I have also come across a diagnostic term, "radiation phobia," to categorize people who presumably suffer excessive anxiety in response to radiation threat. In reality, the psychological trauma actually observed is widespread, making the idea of a pathological response inappropriate. Many Japanese people have experienced such trauma. 


\section{Some Unique Characteristics of Nuclear Trauma}

Unlike many physical traumas, such as an earthquake or tsunami, and unlike many well-defined psychological traumas, one of the principal traumatizing objects here-radiation-is mostly a threat not accessible to the senses. Its effects on physical health are usually delayed and often impossible to isolate, and the extent to which radiation causes physical harm-at low doses, for example-is controversial among experts. The perception of radiation likely relies upon the memory and imagination to take form, so that the psychological trauma becomes one of what may happen, together with distressing background emotions such as fear in the atmosphere of heightened environmental stress. The size of the psychological response would seem to bear little relation to that of the (mathematically) predicted radiation-related physical harm.

Nuclear power itself has a controversial history, is linked in many people's minds to nuclear bombs, and remains a politically loaded issue with strong opponents and proponents. Politicians and political advocates on both sides of the nuclear debate, as well as the media, play an important role in popular perceptions of nuclear power. Many senior Japanese citizens have, of course, experienced extremely traumatic past events, but the psychological relationship between the nuclear bombings of Hiroshima and Nagasaki and current experiences of nuclear power remains unknown.

\section{Do Different People Respond to Trauma Differently?}

Some traumas, such as the devastating tsunami in northern Tohoku, would be experienced by everyone affected as a threat of utmost severity, with profound negative consequences on psychological well-being. The psychological effects of some traumas that are lesser in severity may be greater in people who have experienced multiple previous traumas (a cumulative effect), or those whose coping mechanisms are overpowered by the specific nature of the trauma. Conversely, the effects would be less in individuals who have previously adapted well to similar stressors, perhaps because of particular personal attributes or social factors. In many 
cases of psychological or even physical trauma, a clear correlation does not exist between the stressor and the psychological response. Perhaps stressors have different meanings to people, and people differ in terms of their capacity to cope and adapt. It is also possible that trauma (as long as it is not inherently overpowering) can lead to psychological strength through the development of resilience and the learning of new adaptive capabilities.

Group and cultural experiences are also relevant in response to trauma. Some traumas seem to strengthen group cohesion, and the experience for the individuals in such groups may be that an event becomes less threatening, even empowering. Westerners may think of London's citizens rallying together to face persistent threats of bombing during World War II. In other cases a particular group may be more vulnerable to the effects of trauma as a result of past experiences in its history.

These considerations strengthen the call to listen to the actual lived experience of the victims of trauma and not to make assumptions. In considering the vignettes below, the relevance of the individual, social, and cultural context in certain traumas is clear. This is not to ignore the possibilities for generalizations regarding the psychological effects of, say, radiation release. It is to say that context shapes the victim's trajectory through trauma.

\section{Sociocultural and Historical Context}

\section{Memories: World War II and Minamata}

It is tempting to conclude, as mentioned above, that past trauma experienced by Japan, particularly with the nuclear bombings of Hiroshima and Nagasaki, probably colors current experiences of the Fukushima accident and the release of radiation. However, I have learned from speaking to some Japanese scholars that there are separate terms in Japanese to refer to nuclear bombs and nuclear power. It may be that for the majority of ordinary Japanese people, worries about Fukushima Daiichi have less to do with the physical effects of radiation that were documented after the nuclear bombings and more to do with other issues, such as wor- 
ries about long-term effects on children, or separation from family and community. It may even be possible that the Japanese nation has already integrated the terrible trauma of the nuclear bombings - another reason we must listen to the stories of the Fukushima victims.

The memory of Minamata, however, does seem to play a role in perceptions of the Fukushima Daiichi accident. Several Japanese scholars, and Western scholars who know Japan well, have suggested to me the potential relevance of Minamata (see the article by Shoko Yoneyama in this special issue). One of the common themes emerging in the testimonies of people affected by the Fukushima accident is the historical memory of cover-up of the release of toxic waste that led to Minamata disease. Themes of private-sector cover-up and government collaboration also seem to loom large in perceptions of government behavior in the aftermath of Fukushima Daiichi.

\section{TEPCO, the Government, and the Media}

Similarly, various high-level investigative reports have documented the collusive relationship between the nuclear power supplier, the Tokyo Electric Power Company (TEPCO), the government's regulating agencies, and parts of the media. There have also been reports of a lack of independence of scientists who provide crucial information to the public. Such important contextual factors are of course expected to feature significantly in people's experiences of the Fukushima Daiichi disaster, and do, as shown in the vignettes below.

\section{Local Issues}

Japanese people have deep roots of historical and cultural connection to land and location. For many people, the trauma of the triple disaster, including evacuations that occurred after the radiation release, partly relates to displacement from home, land, and community, and therefore to deep anxiety regarding their return home. Farmers and many others have lost their livelihood, and produce from their land has been symbolically labeled 
"Fukushima," leading to anxiety outside the prefecture and to devastating effects on local agriculture and industry. I have heard stories suggesting that the people of Fukushima Prefecture have been stigmatized, reinforcing their emotional isolation and jeopardizing the healing process. It is as if they are radioactive in the eyes of outsiders. Further afield, in Australia and the United States, for example, some people have also developed anxiety about Japanese produce.

\section{Some Stories About Fukushima Daiichi}

To illustrate the value of the phenomenological approach, where listening to and recording the stories of those affected becomes a primary source of knowledge about the psychological responses to the Fukushima nuclear disaster, I now share some of the experiences of the people whom I interviewed in March 2012, in Fukushima and in Tokyo.

It was difficult at first to locate people who were willing to be interviewed, which was understandable, since I am a foreign researcher coming into a situation of extreme trauma. Moreover, I do not speak Japanese. Nevertheless, after some e-mail communications, the provision of clarification about the aims of the study, and with kind recommendations from people at the Australian National University in Canberra and in Japan, I was able to meet with seven people. As a group these people were intelligent and self-reflective professionals who provided me with a good understanding of how this tragedy has impacted their lives and the lives of others. Japanese people who did not speak English were interviewed through a translator. All interviews were recorded and professionally transcribed, and any personal identifying information removed to ensure confidentiality.

Despite their high levels of education, their anxieties and distress were easily identifiable. I was at all times carefully attuned to their emotional states and cognizant of potential cultural perceptions (in the case of Japanese participants) that appeared "foreign" to me. None of the participants found the interviews distressing in any way; some reported benefit from being able to 
tell their story and share their concerns with a nonjudgmental, listening other.

\section{Participant 1}

P1 is a Japanese professional in Tokyo. He has spent much time in Western countries and speaks fluent English. For him, "nuclear" means something magical-something powerful coming from something so small. It also means something complicated and scientific. But its other side means weapons, something that can cause serious harm and problems for us all, as in Hiroshima and Nagasaki. He remembered reading a particular cartoon as a child that portrayed stories about people losing families, about horrific trauma and radiation illnesses, about soldiers who came back and went crazy - those stories have stuck in his mind in association with nuclear weapons.

Nuclear power is also unique for P1 in that it requires a huge effort involving national governments in order to exist. It has economic benefits, but it's not right; in a way it's like selling oneself, taking a dirty job, something like prostitution.

The accident at Fukushima Daiichi reminded P1 of the situation with Minamata disease, where the company covered it up and government complicity was suspect. This example meant to him that the government cannot really be trusted with such accidents, including Fukushima. There was also the case in the past where the government knowingly purchased and supplied HIV-contaminated blood from the United States. The way governments work, with bureaucrats doing things away from the public while not knowing the facts - that's why they're not trustworthy, P1 feels.

P1 was at work and watching the news on the Internet when he saw the explosion and the white smoke. "My heart stopped," he said. He became fixated on the news, anxious to find out what was going on. He felt a rising fear of death and the "end of it all" coming. "We are going to die. A lot of people are going to die." It made him think of all the apocalypse talk, of the poisoned food from China, of all the different "signs" people had talked about. And of course he had just witnessed the devastating tsunami on the news. 
P1 suddenly didn't want to be alone; he had a sense of wanting "connection," and he felt the need to make sure his family and friends were OK. He later reflected that many other people didn't panic like him, but he himself, especially after listening to a familiar TV reporter whom he knew was "eloquent . . . lying every time he speaks," did feel panic.

$\mathrm{He}$ also vaguely remembers getting images of the atomic bomb and the Vietnam War. He began to experience radiation-as he took a breath, as he imagined himself drinking water, he could almost feel the radiation, or knowing it was coming. This was made more real for him by Internet satellite images sent by a friend of airflow and the radiation spreading over Japan. "Tokyo is right there." He became afraid to go out jogging in case he breathed radiation in, thinking, This is my last jog. Although he couldn't actually feel the radiation, he became strongly aware of his breathing: It might be the last one. Radiation took on its greatest presence when there was a scare about the water being contaminated, "something even more sinister"-it was everywhere, involving everything he did: Is the shower [I am taking] actually more harmful? he wondered. However, after speaking to some experts he knew, he learned that it was more of a risk to children, so his anxiety lessened.

P1 has noticed that many people seemed less worried than he, and perhaps they coped by blocking out information and feelings. Some people just trust the government. Others have felt better by becoming involved, even by going to the affected areas. In some ways, P1 felt conflicted about going overseas for a week to escape the situation, feeling badly that he would be leaving others behind. But that's what he had to do.

\section{Participant 2}

P2 is a Japanese professional who speaks good English, having spent much time abroad. He happens to know a lot about nuclear reactors and their dangers. Like everyone else in Tokyo, he was trying to cope with frequent earthquakes when he heard about the explosion at Fukushima Daiichi. His immediate reaction was, I have to take my family . . . and escape; it's a big thing. . . . it's 
really bad for young kids. He also remembers some scientists saying it could be dangerous for Tokyo.

He described radiation as an invisible "something" that "can destroy our future." "I fear it because I cannot see it . . but if I can sense it, detect it, I am not fearful, because I can tell if it is dangerous. ... If you know what's going to happen, it's not fear. It's danger." Radiation was something that could destroy future generations and the environment in which his children play. It could even potentially destroy everything.

When P2 tried to imagine radiation, he visualized it like pollen-very small particles, yellow, covering everything, and with a terrible smell:

Like the pollen that's everywhere in the Japanese spring and makes people sick. The particles stick to my body forever but I cannot feel them-it's horrible.... If you try and [wash it off] it goes in further, killing my cells. Then, [just one day], there is a big change in my body. ... I cannot drink or eat or walk. I think it's radiation but I have to go to a doctor to make sure. ... It might smell like a gas ... rotten garbage ... decay.

Unlike him, other families were not preparing to leave Tokyo. He himself would have to take his son out of school and move his sick mother. They didn't understand why he wanted to move them to safety, but he felt confident in what he wanted to do-he knew what was going on. He quickly noticed from media reports that the officials were using strange language-technical terms directly translated from English, and they were being selective about what they said. He felt that because of the relationship between the government and TEPCO, and because academics advising the public had been chosen by the government, deception was occurring. The truth was being hidden.

But the fact that other people, including friends and neighbors, decided to stay saddened him. Yet he realized that many people had nowhere to go. To him the situation was destroying the old Japanese way of life-a reliance upon, and cooperation with, one's neighbors, and a focus on the common good. People were being forced by this disaster to be "independent," to make their 
own decisions, something Japanese people would not normally do. There was a loss of cohesion-it was as if Japanese people were becoming more like Americans - they could not trust the government so had to be independent. "We all have to be alone now," he said. The very idea of the Japanese nation was collapsing for him. Japanese trust in authority was gone.

I can only trust myself and my friends. But when I told people to leave, they didn't understand, they didn't believe me, they had nowhere to go.... Cohesiveness with your neighbor is destroyed. In the earthquake, neighbors helped each other. Not with Fukushima ... Authority is gone; that feels like a big black hole in my heart.

The nuclear disaster felt to him to be much worse than the tsunami, because it had destroyed villages, families, and Japanese culture.

\section{Participant 3}

P3 is a Western professional living in Tokyo. For him "nuclear" triggers a complex emotional response-a sense of disgust about modern society, in which nuclear power is offered as a solution to a problem we've caused. Like other debates today, the nuclear debate is "shallow" and indicative of problems at a deep level, P3 believes. It also speaks to him of humanity's disregard for the environment and a sense of superiority over it, as if the environment was just a "tool" for us to exploit.

Fukushima came when everyone was trying to deal with the shock of watching the tsunami, the constant earthquakes, and the disruption to services. The seriousness of the nuclear disaster itself crept in slowly for him over several days, as he listened to what the officials said and forced him to take a "crash course" in nuclear accidents. At first he wondered whether the radiation might poison him, but this concern settled quickly. There was so much information, he had to find his own balance, what made sense to him. But generally he never felt directly threatened"sufficiently" threatened but not "imminently" so. He took some 
precautions such as keeping windows closed and drinking bottled water, but the crisis never overwhelmed him. He remembers sitting with someone whose city and her own house were wiped out by the tsunami, and she couldn't even contact her relatives. This gave him a perspective, a reality check; whatever fears or worries he had were nothing compared to what she was going through.

He didn't worry so much about "ambient" radiation but did worry somewhat about contamination of the food chain. Food had become an "obsession" with some of his friends. Although he stopped eating fish, it was mostly out of concern for oceanic debris from the tsunami being consumed by the fish that were then eaten. He trusted reports that the radiation levels were low, but didn't feel comfortable with the mixing of uncontaminated and contaminated milk, "to bring the average down."

P3 does not consider himself an "antinuclear crusader"; for him, there are more important environmental issues. He would prefer to deal with things at a deeper level—nuclear, in a way, was just a "spot fire" for him. P3 did realize that some other people's reactions were stronger than his. For example, many foreigners left. But his reaction was to go up to the disaster zone and help, which is what he did. "My instinct was not to worry about the nuclear thing. It was to worry about the human tragedy."

P3 sees himself as realistic about environmental pollution in general—he tries to live a "sensible," overall healthy life—which is why he is not paralyzed by the fear of radiation. Some others in his circle have reacted much more emotionally, and he wonders whether that has to do with a general fear of mortality, or whether this disaster has "crystallized" other troubling issues in their lives. In fact, he has noticed how people, both foreign and Japanese, have responded to this situation quite differently. For him, going up to the disaster zone and seeing what tragedies some people have experienced has made him less worried about radiation.

\section{Participant 4}

P4 is a foreigner who lives outside Fukushima City with his Japanese wife and three children; he never had great concerns about nuclear power in Japan until Fukushima. Before the disas- 
ter, nuclear power seemed like a highly technical area, maybe dangerous but a "necessary evil" for a Japan with few natural resources. He would have preferred not to have to live near nuclear reactors, but he didn't previously find it threatening, especially when he considered the high standards of Japanese engineering and safety. In fact, the reactors in the Fukushima Prefecture were not something that often came to mind, or were associated for him (or many others) with the prefecture overall. The reactors were also located in a part of the prefecture in which he had no real connections. But it did once strike him as a little strange that the area where the reactors were located was not so popular to visit—and the least advertised part of the prefecture.

The Fukushima nuclear accident occurred as he, like everyone else, was trying to deal with the earthquakes and news of the tsunami. He was very tired from all the aftershocks and not being able to sleep, and he had been focused on essentials like water, and what to do if the electricity went down. A vague sense of threat emerged when news came of "trouble" at the plant, and then there was the first explosion. It was difficult for him to evaluate what was happening and to be sure what to do. A neighbor of his seemed unconcerned, but as P4 had children, he thought, Better safe than sorry. His wife had already been organizing to evacuate to a relative's place, so they had actually left the day before the big explosion. He watched on the Internet as the radioactivity readings in the prefecture rapidly increased, and he began to worry that this was big and might even reach their new location. It soon became a question about whether to go overseas, where he has relatives. Although at first he felt conflicted about leaving, as things turned out it was easy to go and be safe.

Nevertheless, there was pressure on his Japanese wife to return to work quickly. P4's strongest drive, however, was to remain safe, perhaps make a new life abroad, and it was at this point after the nuclear disaster that, despite speaking Japanese fluently and having lived in Japan for a while, he realized he wasn't really committed to staying in Japan. His wife, however, had determined that the risk was not so high as to make returning and helping out with the relief effort completely unsafe. P4 wasn't so sure and felt deep down that his wife was being foolish, but he 
appreciated what it was like for her and respected her decision. But at times P4 could not accept just how far his Japanese wife's dutiful behavior went. Amid potentially harmful radiation levels, she went back to her workplace to finish off mundane tasks, clean up a little, and try to put things back to normal. This was too much for him, when the safety of his family was uppermost in his mind.

P4 also closely watched the events and official advice on Japanese television, and his perception was that although some things were mishandled, they were mostly honest and admitted that they didn't know everything. He experienced the Western media as misleading, as almost "taking pleasure in someone else's pain." Because he felt that the politicians couldn't know everything, he did the responsible thing and immersed himself in books on radiation.

Radiation declared itself to him mainly through its disrupting effects on his normal routine, on the tensions it caused between himself and his wife, and through feelings of intermittent panic. Although invisible, it could be imagined to some extent, such as in the dust or wind that blew around outside. Radiation can only become a threat "when someone has told you that it's there," he said; otherwise, you'd never know. P4 was also aware that the imagination could have ill effects in this case: One could get carried away. He had been successful in controlling his imagination, but he felt that if he had been pushed any further with stress, it might have been a different story-his imagination might have gotten the better of him.

\section{Participant 5}

P5, a Japanese professional, was interviewed through a translator. He lived and worked in Fukushima and was repairing his home after the earthquake when news of the nuclear accident came. He immediately felt "numb" but soon began to think of his role as head of his family and of his responsibilities to his employer and to the people of Fukushima. Most of his coworkers turned up for work the next day as usual-maybe out of "social pressure," he 
thought. Some said they were old now and preferred to stay at work and help the victims. Others "let their families decide what they should do," a view he considered acceptable given the circumstances, even if it meant they left work.

Such was the case with his own family, too. Both he and his wife had work responsibilities, and responsibilities to the people of Fukushima, but of course they were very worried about their children. He himself was not afraid of dying, as his parents had died when he was young. In fact, he was more worried about the future of the Japanese nation than himself. What if no one could live in Japan because of radiation? He and his wife decided to move their children elsewhere to stay with a relative, even though this was hard. Was it better for the family to stick together in spite of the risk or to be separated to make things safer? Indeed, his own sister who lived in another city decided to leave in spite of her work responsibilities. She came to Fukushima to be with them.

It is a very sad situation in Fukushima, P5 feels, because the older people have had their connections with children broken; many children have been evacuated. Another thing he has noticed is that often when you meet people, the conversation begins with talk about the radiation level. He doesn't think this is good. Of course for the farmers, and for people who run hotels, their whole livelihood is at stake, so he understands if it becomes their focus.

He found the government response to be inadequate. They were hiding information, "as [in] World War II." For example, they only talked about there being "no immediate danger," and lied when they said there had been no meltdown. Also, he said, although they may not have lied about radiation levels, they might have about the effects of particular radiation levels. As in Chernobyl, there are long-term effects, especially on young people, and the government response seemed to him to be ambiguous. The government only shared information when it was absolutely certain, meaning that less certain but still critical information was left out: "The government shares information if the information is 100 percent certain. If it's like 99 percent . . . then they don't share it, [but I want] to know more information even though it's 
uncertain, because then [I have] more options." His perception of the government has always been that it keeps information hidden when the reputation of a certain company or interest group is at stake. "Welfare for them means the welfare of the government, not the people," P5 believes.

The Japanese government is also very sensitive to how other nations view Japan, P5 says, but not about how the Japanese people feel. "Japanese people really . . . don't trust the Japanese government," he insists. Furthermore, because the Japanese government picks and chooses which experts talk to the media, one cannot really trust scientists or other experts.

\section{Participant 6}

P6 is the wife of P5, so with their children, they are a family that has lived through this together and has had to make decisions together. She remembers as a child seeing a commercial on television saying that Fukushima Daiichi is safe. She didn't really understand why they played that commercial, but people took its safety for granted. She could breathe the air, touch the soil, and not worry. When the explosion occurred she went into a state of shock and felt a sense of chaos. Again the words, "It's safe, it's safe," played in her mind, based upon what she was hearing, but she wondered whether it would be safe if she remained in Fukushima-if the radiation accumulated, for example.

She was suspicious that people kept talking positively, but she also wanted to know the negatives, the dangers. But no one talked about that. The safety she took for granted had gone, and now she was in some kind of "in-between" state. And people-some people evacuated, some stayed-also seemed "in between." Should she move the children to safety, or should they all remain together? As some children were being taken away, she wondered whether she was making the right choice. What about what they are saying in the news? All this played over in her mind.

Slowly, as she heard reassurances from the government, she heard other things that counteracted them, so she became doubtful. Now she is more mistrustful. She has also been affected by what people from Tokyo have said: "Fukushima is not a place for 
anyone to live." But actually, she says, sometimes the radiation level in Tokyo is just as high. She checks the radioactivity levels every day and wonders whether it is safe for her children. It is a constant thought. In Fukushima monitors are everywhere, which makes her constantly feel like a "victim." But if there were no radiation monitors around it would be more chaotic-people would imagine things. Although the level is going down, she won't relax until it is zero.

\section{Participant 7}

For P7, a foreign professional, the word "nuclear" has taken on a much stronger importance since Fukushima. Before that it meant "Chernobyl," "power," "the Cold War arms race." It never meant anything positive.

The events of 2011 are all a bit of a blur-everything was intertwined: earthquakes continuously in Tokyo, disruption to services, the reactor explosion. Many people started leaving Tokyo, but she felt bound to stay because of work and her (Japanese) husband's family. But at one point she did leave, to get away from the quakes - and to get some sleep. Osaka was like a different world for her, where everyone seemed happy and unworried.

Different governments issued different advice to their citizens. The French and Germans evacuated, but the Australian Embassy didn't say anything like that-it was confusing for her. Even now she believes they use words that are "sneaky": They talk about no "immediate risk" but don't talk about the long-term effects. The foreign media were probably sensationalizing things, while the local media were downplaying the problems. It was all "very bizarre" to her.

P7 has felt very tired living in Tokyo with the radiation problem. She does not trust information she gets, especially since information is sometimes released months after something bad has happened. She doesn't trust nuclear power here because the regulatory agency for nuclear power is the same one that promotes it.

P7 has recently altered her diet because she is not confident about the information coming out on food safety. One day the 
government arbitrarily raised the safety levels for radioactivity in different food products. How can it suddenly be safe, especially for children with dividing cells? she wondered. She no longer eats food from certain parts of Japan, she only eats fish from overseas, and she drinks bottled water. She "knows" she has ingested cesium, and she is still thinking of leaving, particularly because she has to think about her baby. It is very hard to know whether things are safe. You need to speak to someone who is independent-minded.

Also worrisome is that the government is moving debris from certain areas to Tokyo to burn but won't allow independent testing of the radioactivity. The government just says it's safe, which has made her more suspicious. There was also a situation involving a car that came from the exclusion zone and parked near her house. She found out and remembers getting very stressed: "Even if you take precautions, random things happen," she says. The readings were so high they took the car back to Fukushima.

There has been conflict between P7 and her husband's brother's wife, who said that it was "ridiculous" for P7 to still be worried about food contamination. P7 thinks she may be in denial, but she also appreciates it must be difficult for people from Fukushima because that name now equates with disaster-it is stigmatized.

Before all this happened she thought that she would remain in Japan indefinitely. She feels terrible saying she feels like leaving now. There are other expat mothers who aren't worried at all, and they trust the government.

\section{Conclusion}

One way of gaining knowledge about the psychological needs of victims of a nuclear accident is to listen to their stories. In a research situation, that approach presents us with rich and relevant data that can also produce rigorous knowledge when analyzed. Of course there is a trade-off between the in-depth understanding gained and the more general but impersonal understanding resulting from quantitative approaches such as popula- 
tion surveys. The two approaches can be complementary rather than opposed.

In my time in Fukushima and Tokyo, a number of themes emerged with implications for professionals tasked with helping the victims:

1. We cannot take for granted that any Western model of trauma is entirely appropriate to the Fukushima situation for the Japanese people. We must put our theories aside and ask them. Empathic attunement to the experiences of victims is important and may even have therapeutic benefits.

2. The release of nuclear radiation has characteristics that suggest it could be quite different from other physical and psychological traumas, with invisibility, delayed effects, and scientific controversy about the risk of harm being important features.

3. Understanding the psychological effects of the Fukushima Daiichi accident calls for close attention to local issues, culture, and the individual and communal history of those affected. Although some issues may be universal, many may be "local" - there is no "one size fits all" here, no matter how much easier that would make response planning.

4. In the Japanese context, family and community well-being and cohesiveness seem more important than individual needs.

5. Not everything is known about the long-term effects of radiation. It is paramount for leaders to be honest and transparent about this.

6. Populations or groups suffering severe trauma are vulnerable and need to experience reliable and trustworthy leadership to cope. They are particularly vulnerable to the natural human tendency to mistrust.

7. The fear of radiation may involve a number of other fears, some of which are activated because of anxiety and not necessarily related to the radiation threat. Helping the public manage anxiety overall is just as important as helping them deal with radiation concerns. 


\section{Notes}

Michael Edwards is a practicing psychiatrist in Sydney, Australia, and a doctoral candidate in the Colleges of Science at the Australian National University in Canberra. His academic interests center on psychoanalysis and social phenomena, as well as on modern physics. His current doctoral project explores people's perceptions of nuclear power from a phenomenologicalpsychoanalytic perspective. He can be reached at michael.edwards@anu .edu.au. I wish to thank my Japanese friends and colleagues, Japan scholars at the Australian National University, and most importantly my study participants, who have all helped me greatly in understanding the situation that Japan has experienced and continues to face, and for instigating my very early journey into Japanese language, culture, and history. In particular I wish to thank Kenichi Tokoi, Kent Anderson, Tessa Morris-Suzuki, Peter Van Ness, Shigeru Iwakabe, Mitsuyasu Oda, and Yuichi Murakami.

1. For an excellent overview, see Giorgi 2009.

\section{References}

Giorgi, Amedeo. 2009. The Descriptive Phenomenological Method in Psychology: A Modified Husserlian Approach. Pittsburgh, PA: Duquesne University Press.

Polkinghorne, Donald. 1983. Methodology for the Human Sciences: Systems of Inquiry. Albany: State University of New York Press. 
Reproduced with permission of the copyright owner. Further reproduction prohibited without permission. 